\title{
Embryology of Anoectochilus roxburghii: seed and embryo development
}

\author{
Yuan-Yuan $\mathrm{Li}^{1+}$, Zhi-Xia Meng ${ }^{1 \dagger}$, Ying Zhang ${ }^{1}$, Shun-Xing Guo ${ }^{1 *}$ and Yung-I Lee $2,3^{*}$ (D)
}

\begin{abstract}
Background: Anoectochilus roxburghii is known for its medicinal properties, culinary interests, and ornamental applications in Asian countries. Recent studies focus mainly on its phytochemical properties and little is known about its reproductive biology, especially seed and embryo development. This study documents the major developmental events in seed and embryo development of A. roxburghii upon pollination.

Results: Morphological and histological studies revealed that upon pollination embryo and seed development is completed in 40 days. Ovular primordia are at the megaspore mother cell stage at the time of anthesis. Embryo development proceeds after a successful fertilization. A. roxburghii has a single cell suspensor. It elongates but not extended beyond the seed coat. A distinct cell gradient is present within the embryo proper with smaller cells located towards the chalazal end of the seed. Proteins and lipids are the major storage products within the embryo proper cells. At the stage of early globular embryo, the inner seed coat has degenerated and thus a carapace is absent at maturity. A limited deposition of lignin is detected in the mature seed coat.

Conclusions: The seed of A. roxburghii matures rapidly. At maturity, the embryo proper has a well-differentiated apical zone with little constraints impose by the seed coat. These characters indicate adaptations to fast germination that may ensure a successful colonization in the shaded forest understory.
\end{abstract}

Keywords: Embryogenesis, Jewel orchid, Seed coat, Suspensor

\section{Background}

The genus Anoectochilus, commonly known as marbled jewel orchids, is a small terrestrial orchid in subtropical and tropical regions. It comprises about 60 species native to habitats ranging from the Himalayas to south China and southeast Asia, Australia, New Guinea and Melanesia (Pridgeon et al. 2003; Govaerts 2018). Anoectochilus roxburghii has medicinal, culinary, and ornamental applications in several Asian countries (Chen et al. 2009). In traditional medicine, the whole plant can be used for heat dissipation, elimination of dampness, detoxification, and

\footnotetext{
*Correspondence: sxguo1986@163.com; leeyungi@hotmail.com

${ }^{\dagger}$ Yuan-Yuan Li and Zhi-Xia Meng contributed equally to this work

1 Institute of Medicinal Plant Development, Chinese Academy of Medical

Sciences \& Peking Union Medical College, Beijing 100193,

People's Republic of China

${ }^{2}$ Biology Department, National Museum of Natural Science, No 1,

Kuan-Chien Rd, Taichung 40453, Taiwan

Full list of author information is available at the end of the article
}

immunity enhancement (Ye et al. 2017). A. roxburghii likes to grow in the humus-rich soil under broad leaf and evergreen primary forests at elevations of $300-800 \mathrm{~m}$ above sea level. During October to December, the flower spikes are up to $25 \mathrm{~cm}$ tall and each spike produces $2-6$ flowers near $1 \mathrm{~cm}$ in diameter (Chen et al. 1999). Nowadays, because of huge market demands, wild populations of $A$. roxburghii have decreased sharply due to over-collection.

Similar to other orchid species, the tiny $A$. roxburghii seed has a rudimentary embryo and lacks endosperm (Arditti and Ghani 2000; Yam et al. 2002). Seed germination requires mycorrhizal association, which supplies nutrients for the germinating seed until the seedling develops green leaves and becomes autotrophic (Rasmussen 1995). Until now information of reproductive development in orchid species in the subtribe Goodyerinae is limited. The objectives of this study were to document key developmental and anatomical events in 
the embryogenesis of $A$. roxburghii. Besides morphological characterization, we used the Historesin embedding method to provide high quality serial sections to examine developmental events during the course of seed development. The observation provides essential knowledge for future investigations into the reproductive biology of $A$. roxburghii.

\section{Methods}

\section{Plant materials}

Plants of $A$. roxburghii were grown in the greenhouse at the Institute of Medicinal Plant Development, Chinese Academy of Medical Sciences \& Peking Union Medical College, Beijing, China. Blooming of $A$. roxburghii usually occurred from October to December. To guarantee a good capsule set and seed quantity, flowers were hand-pollinated at the time of anthesis (Fig. 1). Developing capsules were harvested at regular intervals after pollination. Around 90 developing capsules were harvested for this study.

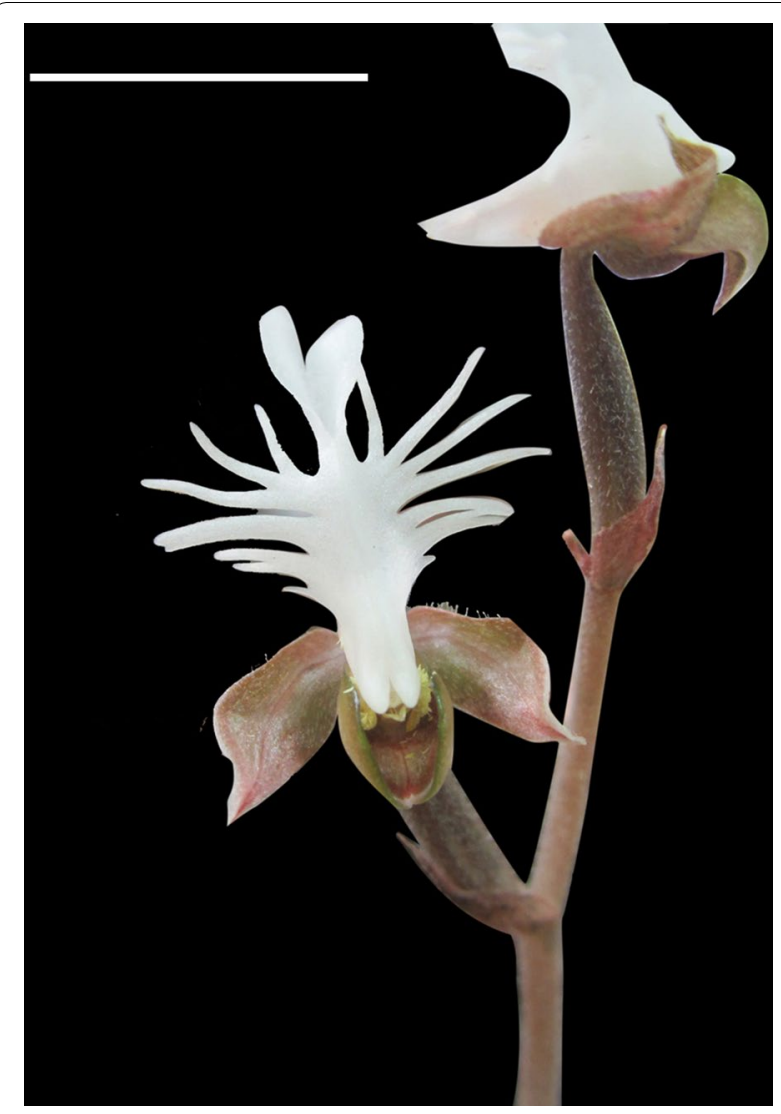

Fig. 1 The flower of A. roxburghii. Scale bar $=1 \mathrm{~cm}$

\section{Light microscopy and histochemical observations}

Development capsules were sliced and fixed immediately with $2.5 \%$ glutaraldehyde in $0.1 \mathrm{M}$ phosphate buffer, $\mathrm{pH} 6.8$ at room temperature for $6 \mathrm{~h}$. After fixation, the samples were dehydrated using an ethanol series, and embedded in Technovit 7100 (Kulzer \& Co., Germany) as described by Yeung and Chan (2015). Serial, $3 \mu \mathrm{m}$-thick sections were cut using glass knives by a Reichert-Jung 2040 Autocut rotary microtome. These sections were collected on slides and stained with Periodic acid-Schiff's reaction for total insoluble carbohydrates, and counterstained with either $0.05 \%(\mathrm{w} / \mathrm{v})$ toluidine blue O (TBO) in the benzoate buffer for general histology or $1 \%(\mathrm{w} / \mathrm{v})$ amido black $10 \mathrm{~B}$ in the $7 \%$ acetic acid solution for protein staining (Yeung 1984). The presence of cuticular material was stained using Nile red as described by Lee et al. (2006). The sections were stained with $1 \mu \mathrm{g} \mathrm{ml}^{-1}$ of Nile red (Sigma Chemical Co., St. Louis, Mo.) for $3 \mathrm{~min}$, briefly washed in distilled water for $1 \mathrm{~min}$, and mounted in the Vectashield ${ }^{\circledR}$ anti-fading medium (Vector Laboratories, Inc., Burlingame, CA). The fluorescence signal was examined using an epifluorescence microscope (Axioskop 2, Carl Zeiss AG) equipped with the Zeiss filter set. The images were captured digitally using a CCD camera attached to the microscope.

\section{In vitro seed germination}

The mature seeds were collected from capsules and surface sterilized with a $0.5 \%$ sodium hypochlorite solution with $0.1 \%$ wetting agent (Tween 20) for $15 \mathrm{~min}$. After sterilization, the seeds were rinsed three times in sterile distilled water. The seeds were inoculated onto the 1/4 Murashige and Skoog (MS) medium (Murashige and Skoog 1962), supplemented with $2 \mathrm{mg} \mathrm{l}^{-1}$ glycine, $0.5 \mathrm{mg} \mathrm{l}^{-1}$ niacin, $0.5 \mathrm{mg} \mathrm{l}^{-1}$ pyridoxine $\mathrm{HCl}, 0.1 \mathrm{mg} \mathrm{l}^{-1}$ thiamine, $1 \mathrm{~g} \mathrm{l}^{-1}$ tryptone, $20 \mathrm{~g} \mathrm{l}^{-1}$ sucrose, $100 \mathrm{ml} \mathrm{l}^{-1}$ coconut water and solidified with $7 \mathrm{~g} \mathrm{l}^{-1}$ agar (SigmaAldrich Co.). The $\mathrm{pH}$ of the medium was adjusted to 5.6 before autoclaving at $121{ }^{\circ} \mathrm{C}$ for $15 \mathrm{~min}$. After sowing, the cultures were incubated in the dark at $25 \pm 1{ }^{\circ} \mathrm{C}$. Each culture tube was examined at 15-day intervals for 60 days in culture under a stereomicroscope. Germination was considered as emergence of the embryo from the testa.

\section{Results}

Table 1 describes major developmental events and changes in structure, size and color of capsules and seeds of $A$. roxburghii from pollination to seed maturity. The un-pollinated ovary was dark reddish-green in color covered with epidermal hairs. Upon a successful pollination, flowers senesced quickly and ovaries began to enlarge and turned into capsules (Fig. 2). As the capsules 
enlarged, the color turned into light reddish-green to light reddish-brown from 5 to 20 days of pollination (DAP). As the capsules approached maturity, the color became reddish brown at $30 \mathrm{DAP}$, and the capsules split to release seeds at 40 DAP.

At the time of anthesis, ovular primordia were well developed within ovaries (Fig. 3a). Upon pollination, the primordia elongated rapidly (Fig. 3b-e). After fertilization, the seed coat continued to elongate and the color of seeds turned from white to yellow (Fig. 3e, f). As the seeds approached maturity at $40 \mathrm{DAP}$, the hair-like seeds became light-brown and desiccated (Fig. 3g). Seed maturation took 40 days from the time of pollination (Table 1).

Ovule development had begun during flower development. At the time of anthesis, the ovular primordia were

Table 1 Major developmental events occurring in developing capsules of $A$. roxburghii after fertilization

\begin{tabular}{|c|c|c|c|c|c|c|c|}
\hline \multirow[t]{2}{*}{ DAP } & \multirow[t]{2}{*}{ Developmental stage } & \multicolumn{2}{|c|}{ Capsule size (mm) } & \multirow[t]{2}{*}{ Capsule color } & \multicolumn{2}{|c|}{ Seed size $(\mu \mathrm{m})$} & \multirow[t]{2}{*}{ Seed color } \\
\hline & & $\mathrm{X}$-axis & Y-axis & & $\mathrm{X}$-axis & Y-axis & \\
\hline 0 & Megaspore mother cell & $2.36 \pm 0.02$ & $12.71 \pm 0.03$ & Dark reddish green & $59.4 \pm 7.4$ & $163.9 \pm 10.2$ & White \\
\hline 5 & Mature embryo sac & $2.91 \pm 0.05$ & $13.54 \pm 0.02$ & Light reddish green & $62.6 \pm 6.9$ & $268.6 \pm 12.1$ & White \\
\hline 10 & Fertilization and zygote & $3.69 \pm 0.06$ & $13.43 \pm 0.08$ & Light reddish green & $74.2 \pm 10.7$ & $583.3 \pm 9.4$ & White \\
\hline 15 & Proembryo & $3.81 \pm 0.08$ & $13.62 \pm 0.09$ & Light reddish brown & $85.3 \pm 7.4$ & $1085.7 \pm 16.5$ & White \\
\hline 20 & Early globular to globular embryo & $3.94 \pm 0.11$ & $13.81 \pm 0.07$ & Light reddish brown & $89.5 \pm 14.1$ & $1732.2 \pm 22.9$ & Yellowish white \\
\hline 30 & $\begin{array}{l}\text { Late globular embryo, and the } \\
\text { suspensor starts to degenerate }\end{array}$ & $4.12 \pm 0.12$ & $13.75 \pm 0.11$ & Reddish brown & $89.9 \pm 12.5$ & $2015.1 \pm 29.2$ & $\begin{array}{l}\text { A mixture of yellowish } \\
\text { white and light brown } \\
\text { seeds }\end{array}$ \\
\hline 40 & Mature seed & $3.92 \pm 0.06$ & $13.48 \pm 0.08$ & Reddish brown & $87.1 \pm 14.1$ & $2064.5 \pm 35.2$ & Light brown \\
\hline
\end{tabular}

DAP, days after pollination

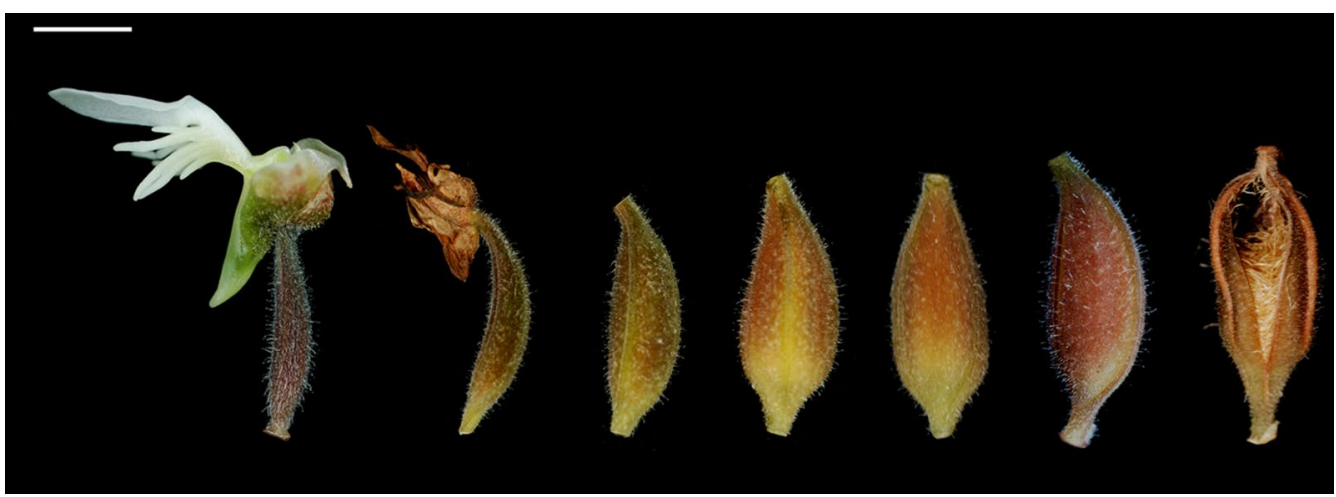

Fig. 2 Light micrographs of developing capsules of A. roxburghii. From left to right, 0, 5, 10, 15, 20, 30 and 40 DAP. Scale bar = 5 mm

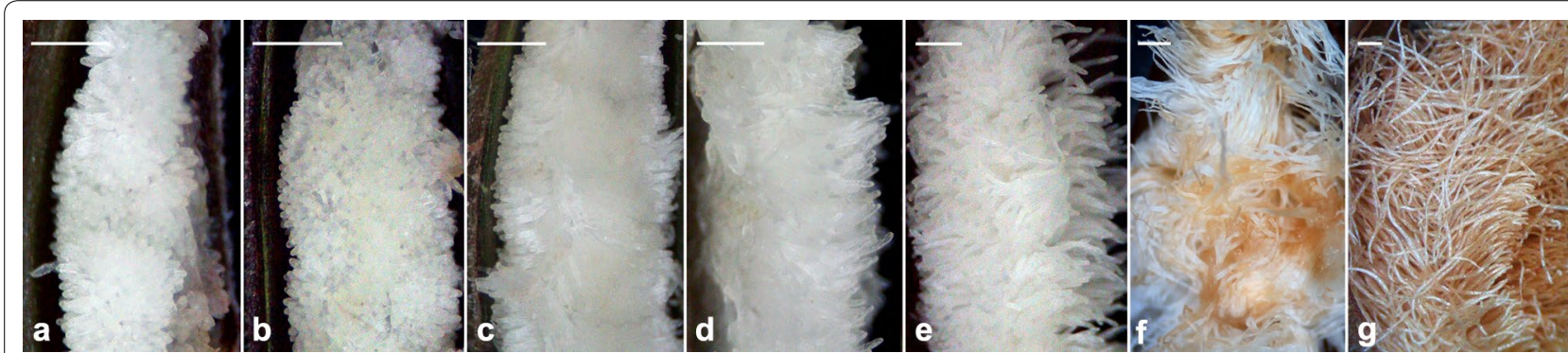

Fig. 3 Light micrographs of developing ovules and seeds of A. roxburghii. a 0 DAP, b 5 DAP, c 10 DAP, d 15 DAP, e 20 DAP, f 30 DAP and $\mathbf{g}$ at 40 DAP. Scale bar $=0.5 \mathrm{~mm}$ 
at the megaspore mother cell stage. It took only 40 days for an ovule to develop into a mature seed (Fig. 4). At 5 DAP, the megaspore mother cell enlarged and differentiated into an embryo sac (Fig. 4a). Fertilization occurred approximately $10 \mathrm{DAP}$, and embryo development soon commenced. The zygote initially had an ovoid shape (Fig. 4b), then it elongated and became highly polarized (Fig. 4c). The first cell division of the zygote was unequal, producing a smaller terminal cell and a larger basal cell (Fig. 4d). The terminal cell formed the embryo proper while the basal cell gave rise to the suspensor. Moreover, derivatives from the basal cell also contributed cells to the embryo proper. The endosperm failed to develop in this species. After fertilization, the nuclei within the primary endosperm cell did not undergo further division (Fig. 4b). The content of the cell was eventually absorbed by the expanding embryo.

\section{Suspensor development}

Anoectochilus roxburghii has only a single suspensor cell and it is elongated as it matured. The cell lineage resulting in suspensor formation is described as follows. An additional transverse cell division occurred in the twocelled embryo resulting in the formation of a three-celled embryo (Fig. 4e). This was soon followed by a transverse division occurring in the larger basal cell (Fig. 4f), giving rise to a four-celled embryo (Fig. 4g). The micropylar basal cell enlarged in size and destined to become the suspensor (Fig. 4g). When compared to the other three cells toward the chalazal end, the micropylar basal cell was more cytoplasmic with many small vacuoles present. This micropylar basal cell elongated rapidly by the process of vacuolation (Fig. 4h, i). It is notable that starch granules were present in the suspensor cell but less abundant in the embryo proper at this time (Fig. 4h, i). The suspensor cell continued to elongate and finally extended beyond the micropylar opening of the inner seed coat and grew into the lumen enclosed by the outer seed coat (Fig. 4i). However, the suspensor cell never extended beyond the outer seed coat. As the embryo matured, the suspensor cell became dehydrated and finally collapsed (Fig. 5f). The pattern of Nile red staining indicated that a cuticular substance was absent over the walls of the suspensor cell through its development and maturation (Fig. 5g, h).

\section{Embryo proper development}

In the four-celled embryo, the three cells towards the chalazal end were responsible for the formation of the embryo proper (Fig. 4g). The cells at the terminus of the filamentous embryo began to divide vertically and these newly formed cells enlarged in preparation for further divisions (Fig. 5a). Additional periclinal and anticlinal divisions occurred within the embryo proper, resulting in the formation of an inner tier of cells and the protoderm (Fig. 5c). A distinct protoderm layer was found at approximately 20 DAP, and a number of starch grains had accumulated within the cells of embryo proper (Fig. 5d). As the seed approached maturity (30 DAP), starch grains became more abundant (Fig. 5e).

At maturity (40 DAP), the ellipsoidal embryo was only seven to eight cells along its long axis and four cells across. The cells were of different sizes. The cells toward the chalazal end were smaller than those toward the micropylar end (Fig. 5f). Within the cells of a mature embryo proper, only a few starch grains could be observed; protein and lipid bodies became the major storage products. Nile red staining indicated the presence of cuticular substance in the wall appeared at the early globular stage of embryo development (Fig. 5g). The same staining pattern persisted through embryo

\footnotetext{
(See figure on next page.)

Fig. 4 Light micrographs of embryo development of A. roxburghii at the early stages. a Light micrograph of a mature embryo sac before fertilization at 5 DAP. The egg cell (E) has an elongated shape with a prominent vacuole toward the micropylar end. Antipodal cells (arrowheads), inner seed coat (IS), outer seed coat (OS), polar nucleus (arrow), synergid (S). Scale bar $=30 \mu \mathrm{m}$. b Light micrograph of the zygote (Z) after fertilization at 10 DAP. At the micropylar end, one synergid has degenerated (DS), and the other synergid is still persistent (PS). The primary endosperm nucleus (arrow) could be observed within the endosperm cavity, but the endosperm eventually fails to develop. Antipodal cells (arrowheads), inner seed coat (IS), outer seed coat (OS). Scale bar $=30 \mu \mathrm{m}$. c An elongated zygote (double arrowhead) with a prominent vacuole (V) toward the micropylar end. No additional division of the endosperm nucleus (arrow) is observed. Inner seed coat (IS), outer seed coat (OS). Scale bar=30 $\mu$ m. $\mathbf{d}$ The first cell division of the zygote produces a smaller terminal cell (T) and a larger basal cell (B). Inner seed coat (IS), outer seed coat (OS). Scale bar = $30 \mu \mathrm{m}$. e Light micrograph showing a three-celled embryo (arrowheads), and the endosperm nucleus (arrows) has become condensed. Inner seed coat (IS), outer seed coat (OS). Scale bar $=30 \mu \mathrm{m}$. f The alignment of metaphase chromosomes (arrow) indicates a transverse division occurring in the basal cell of a three-celled embryo. Inner seed coat (IS), outer seed coat (OS). Scale bar $=30 \mu \mathrm{m}$. $\mathbf{g}$ A four-celled embryo resulting from the transverse division of the basal cell. The cell towards the micropylar end has become larger with a prominent nucleus and numerous small vacuoles (arrows). The cell accumulates numerous small vacuoles in preparation for the further cell elongation. Inner seed coat (IS), outer seed coat (OS). Scale bar $=30 \mu \mathrm{m}$. $\mathbf{h}$ Light micrograph showing a filamentous-shaped embryo. The suspensor cell (S) with a prominent vacuole has enlarged and elongated toward the micropylar end. A few tiny starch granules (arrowheads) are present in the suspensor cell. Inner seed coat (IS), outer seed coat (OS). Scale bar $=30 \mu \mathrm{m}$. i The suspensor cell (S) elongates rapidly with numerous starch granules (arrowheads) and has protruded into the cavity enclosed by the outer seed coat (OS). At this stage, the inner seed coat (IS) is degenerating (arrow). Scale bar $=30 \mu \mathrm{m}$
} 


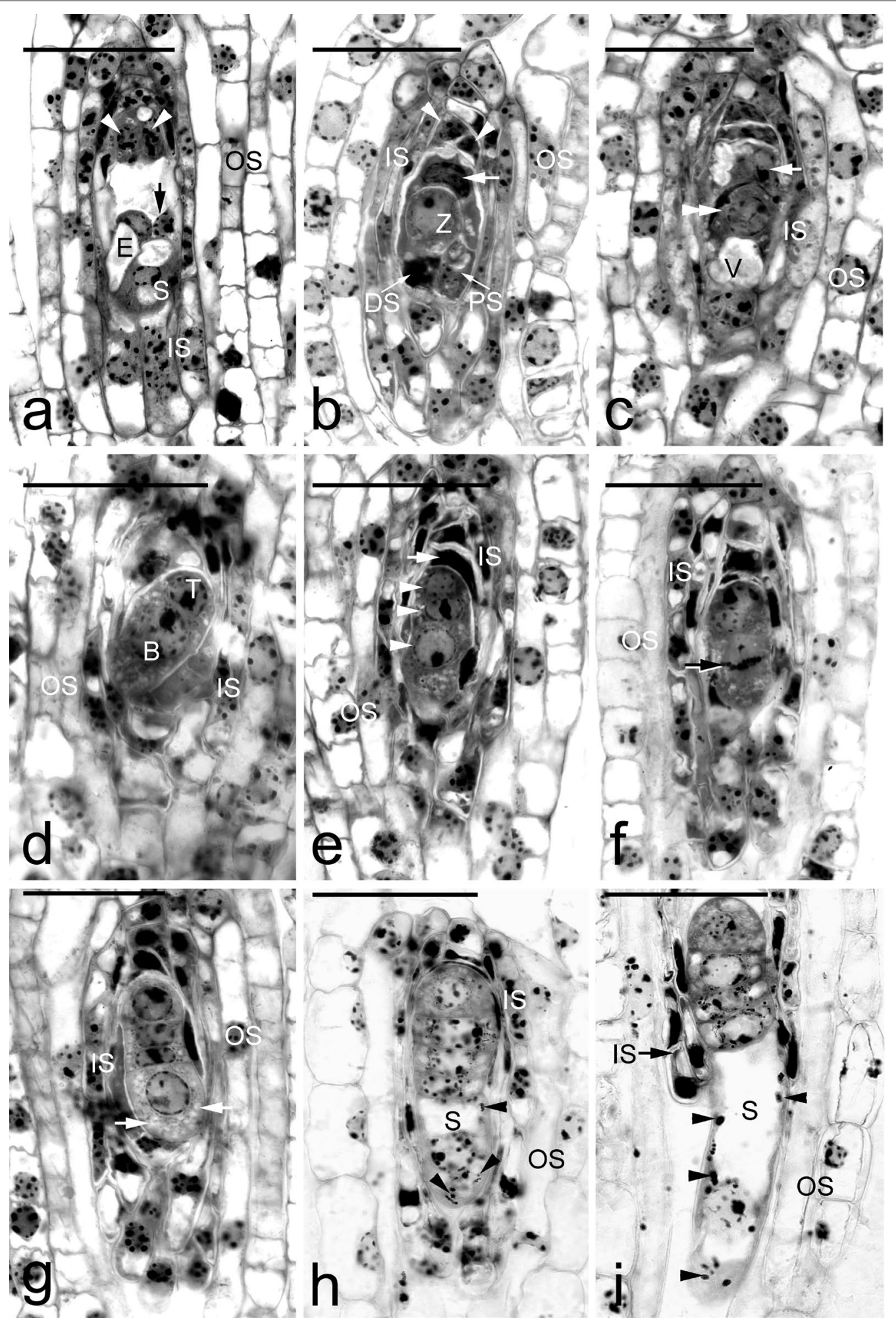



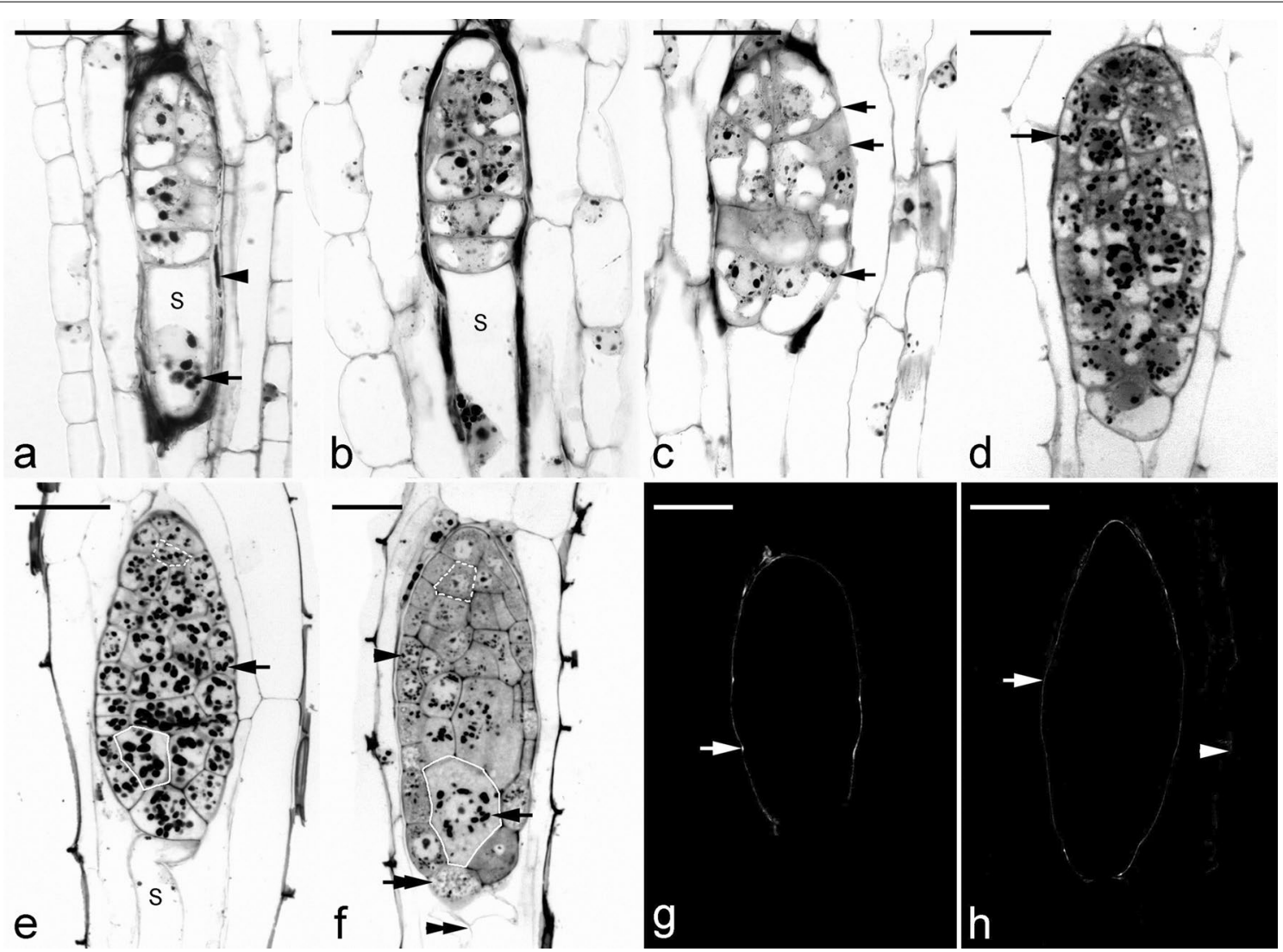

Fig. 5 Light micrographs of embryo development of A. roxburghii at the late stages. a The cell at the terminus divides vertically and increases in size in preparation for further divisions. The suspensor ( $S$ ) continues to elongate and a few starch grains (arrow) accumulate around the nucleus. At this stage, the inner seed coat has degenerated (arrowhead) and has been resorbed by the developing embryo. Scale bar $=30 \mu \mathrm{m}$. $\mathbf{b}$ The suspensor has elongated further, but it never extends beyond the lumen enclosed by the outer seed coat. Scale bar $=30 \mu \mathrm{m}$. $\mathbf{c}$ Additional periclinal and anticlinal divisions within the embryo proper that result in the formation of the inner tier of cells and the protoderm (arrows). Scale bar $=30 \mu \mathrm{m}$. d Light micrograph showing an early globular embryo with a discernible protoderm. Numerous starch grains (arrow) accumulate within the cells of embryo proper. Scale bar $=30 \mu \mathrm{m}$. e As the globular embryo approaches maturity, more starch grains (arrow) accumulate within the embryo proper and the suspensor (S) is going to degenerate. Within the embryo proper, the smaller cell toward the chalazal end is marked by the dashed line and the larger cell toward the micropylar end is marked by the solid line. Scale bar $=30 \mu \mathrm{m}$. $\mathbf{f}$ A longitudinal section through a mature seed. Within the embryo proper, the smaller cell toward the chalazal end is marked by the dashed line and the larger cell toward the micropylar end is marked by the solid line. The suspensor cell (double arrowhead) became dehydrated and finally collapsed. At this stage, the starch grains (arrow) have most disappeared, and numerous small protein bodies (arrowhead) can be seen within the embryo proper. Although the lipid cannot be preserved in this historesin, the spaces between the protein bodies could be the storage lipid bodies (double arrow). Scale bar $=30 \mu \mathrm{m}$. $\mathbf{g}$ Nile red staining fluorescence micrograph of an early globular embryo at the same stage as that seen in c. The surface wall (arrow) of the embryo proper reacts positively to the stain, and the fluorescence is absent in the suspensor wall. Scale bar $=30 \mu \mathrm{m}$. $\mathbf{h}$ Nile red staining fluorescence micrograph of a globular embryo at the same stage as that seen in $\mathbf{e}$. The surface wall (arrow) of the embryo proper reacts positively to the stain, and seed coat (arrowhead) only reacts weakly. Scale bar $=30 \mu \mathrm{m}$

maturation, and the staining intensity did not increase as the embryo matured (Fig. 5h).

\section{Seed coat development}

After fertilization, the inner and outer integuments became the seed coat enclosing the developing embryo (Fig. 4b-g). During the early stages of embryo proper formation, the cells of the inner seed coat progressively degenerated (Fig. 4h-i), and their cell content was apparently absorbed by the developing embryo (Fig. 5a). At the early globular stage, the outer seed coat was two cells thick, and the cell walls of the outermost layer of the seed coat stained purple with the TBO stain, indicating the absence of phenolic compounds in the wall (Fig. 5c). In addition, Nile red staining gave no fluorescence signal from the walls of the outer seed coat (Fig. 5g). As the seed approached maturity, the cells of the seed coat became dehydrated and compressed into a thin layer (Fig. 5e-f). The radial walls of the outermost layer of the seed coat gave a greenish blue color when stained with 
TBO, indicating the presence of phenolic compounds in the wall (the lignification of cell wall). In addition, the secondary walls reacted weakly to Nile red stain (Fig. 5 h).

\section{In vitro seed germination}

At 15 days after inoculation, the embryo started to enlarge and protrude from the seed coat on $1 / 4 \mathrm{MS}$ medium. Seed germination reached $72.5 \%$ after 60 days of inoculation (Additional file 1: Figure S1).

\section{Discussion}

As shown in Table 1, embryo development and seed maturation in $A$. roxburghii is rapid compared to many orchid species. One of the main reasons is that ovule development commences prior to pollination. In most orchids, ovule development is delayed and triggered by pollination (Yeung and Law 1997). The orchids with a relative rapid ovule development, e.g. Epipogium aphyllum (Afzelius 1954), Epipactis papillosa (Sato 1974) and Gastrodia elata (Kusano 1915) usually have megaspore mother cells and/or embryo sacs present within the ovary at the time of anthesis. In A. roxburghii, megaspore mother cells could be observed within the ovary at the time of anthesis, and mature embryo sacs are present at 5 DAP (Additional file 2: Figure S2). It is noteworthy that many orchids with a rapid process of embryo development are terrestrial species occurring in the shaded forest understorey. A rapid seed maturation may ensure a rapid seed dispersal, and thus a successful colonization strategy when growing in the shaded forest understorey.

Most orchids have rudimentary embryos and without a defined tissue pattern. Generally, only a protoderm has differentiated, and depending on the species, a gradient of cell sizes within the embryo proper can be seen with smaller cells located at the chalazal end, denoting the future shoot pole (Andronova 2006). The presence of a well-differentiated apical zone could provide not only an indication of structural differentiation but also an indirect indication on the difficulty in seed germination. In the easy-to-germinate species, such as Epidendrum (Yeung 2017), Phalaenopsis (Lee et al. 2008) and Anoectochilus in this study, a marked gradient of cell size exits in the embryo proper of their mature seeds. While in the difficult-to-germinate species such as Calanthe (Lee et al. 2007), Calypso (Yeung and Law 1992) and Cypripedium (Lee et al. 2005), their embryo proper has cells of similar sizes. The gradient of cell sizes reveals the existence of physiological differences along the embryo in an apical-basal manner. The welldifferentiated apical zone within the embryo proper may accelerate the differentiation in shoot apical meristem within a protocorm upon seed germination in asymbiotic cultures (Lee et al. 2013; Yeung 2017). It is also interesting to note the formation of large embryo cells near the micropylar end (Fig. 5e, f). This portion of embryo proper are programmed to house the symbiont in germination. During embryo development, the suspensor cell wall and the cell wall of the large cell adjacent to the suspensor cell are free of cuticle coverage. As the suspensor degenerated at seed maturity, the large cell at the basal end provides a ready entry point for the penetration of mycorrhizal fungi (Jiang et al. 2015). In addition, the persistence of starch grains in the larger cells (Fig. 5f) may serve as an enticement for fungal hyphae.

In developing seeds of orchids, the accumulation of lignin and/or cuticular materials in different layers of the seed coat has been reported in a number of orchids, such as Apostasia (Nishimura and Tamura 1993), Calanthe (Lee et al. 2007), Cephalanthera (Yamazaki and Myoshi 2006), Cymbidium (Yeung et al. 1996), Cypripedium (Lee et al. 2005), Cyrtosia (Yang and Lee 2014), Paphiopedilum (Lee et al. 2006) and Vanilla (Nishimura and Yukawa 2010). The differences in accumulation of lignin and cuticular materials may affect the seed germination in vitro (Yeung et al. 2018). In those difficultto-germinate species, the inner integument usually forms a thin layer of inner seed coat, termed 'carapace' tightly enclosing the embryo, such as Cephalanthera (Yamazaki and Myoshi 2006), Cypripedium (Lee et al. 2005) and Dactylorhiza (Rasmussen 1995). The thickness of the carapace and the accumulation of cell wall materials, e.g. lignin and/or cuticular materials can be diverse among orchid species. Lignification and cutinization could strengthen the cell walls of seed coat and thus protect the minute embryo at the time of seed dispersal. But the tightly fitted coating forms a physical barrier restricting embryo growth (Miyoshi and Sato 1997). On the other hand, for the easy-to-germinate species (especially the epiphytic orchids), such as Phalaenopsis (Lee et al. 2008), the inner seed coat degenerates soon after fertilization, and the lignification only occurs at the radial wall of seed coat forming a discontinuous layer covering the embryo. Seed germination of Anoectochilus species is not recalcitrant (Additional file 1: Figure S1, Chou and Chang 2004) as compared to a majority of temperate terrestrial orchids (Lee et al. 2005; Yamazaki and Myoshi 2006). This is likely due to the absence of a distinct carapace. Histochemical staining results indicated an absence of cuticular material in the seed coat and a limited deposition of lignin. These characters may enable the embryo of $A$. roxburghii to access water and nutrients from the environment. Furthermore, there is a less physical restriction to subsequent seed enlargement and germination. 


\section{Conclusions}

The developmental timetable summarizes major developmental events in seed and embryo development of $A$. roxburghii upon pollination. At maturity, the marked gradient of cell size in the embryo proper may accelerate the differentiation and formation of a shoot apical meristem within a protocorm upon germination. Together with little constraints impose by the seed coat, A. roxburghi seeds germinate readily. The information provided in this study serve as a quick handy reference for future in vivo and in vitro studies of embryo development and seed germination.

\section{Additional files}

Additional file 1: Figure S1. In vitro seed germination rate of $A$. roxburghii on 1/4 MS medium. Error bars represent SE $(n=3)$.

Additional file 2: Figure S2. In A. roxburghii, the megaspore mother cell (M) could be observed within the ovary at the time of anthesis (A), and the mature embryo sac is present at 5 DAP (B). Egg (E), polar nucleus (P), synergids (S). Scale bar $=50 \mu \mathrm{m}$.

\section{Authors' contributions}

LYI and GSX conceived the study. LYI, GSX, LYY and MZX designed the study. MZX, GSX and LYI provided funding. LYI, LYY and ZY performed experiments. $L Y I, G S X$ and LYY wrote the paper. All authors read and approved the final manuscript.

\section{Author details}

${ }^{1}$ Institute of Medicinal Plant Development, Chinese Academy of Medical Sciences \& Peking Union Medical College, Beijing 100193, People's Republic of China. ${ }^{2}$ Biology Department, National Museum of Natural Science, No 1, Kuan-Chien Rd, Taichung 40453, Taiwan. ${ }^{3}$ Department of Life Sciences, National Chung Hsing University, Taichung 40227, Taiwan.

\section{Acknowledgements}

The authors thank the Lee laboratory members for the assistance on sectioning plastic blocks.

\section{Competing interests}

The authors declare that they have no competing interests. The founding sponsors had no role in the design of the study; in the collection, analyses, or interpretation of data; in the writing of the manuscript, and in the decision to publish the results.

\section{Availability of data and materials}

Not applicable.

\section{Consent for publication \\ Not applicable.}

\section{Ethics approval and consent to participate}

Not applicable.

\section{Funding}

This work was supported by Grants from CAMS Innovation Fund for Medical Sciences (CIFMS) (2017-12 M-3-013).

\section{Publisher's Note}

Springer Nature remains neutral with regard to jurisdictional claims in published maps and institutional affiliations.
Received: 23 January 2019 Accepted: 9 April 2019

Published online: 22 April 2019

\section{References}

Afzelius K (1954) Embryo-sac development in Epipogium aphyllum. Svensk Botany Tidskr 48:513-520

Andronova EV (2006) Embryogenesis in Orchidaceae. In: Batygina TB (ed) Embryology of flowering plants, vol 2. Seed. Science Pub, New Hampshire, pp 355-359

Arditti J, Ghani AKA (2000) Numerical and physical properties of orchid seeds and their biological implications. New Phytol 145:367-421

Chen SC, Tzi ZH, Luo YB (1999) Native orchids of China in colour. Science Press, Beijing

Chen X, Gale SW, Cribb PJ, Ormerod P (2009) Anoectochilus Blume. Flora China 25:76-80

Chou LC, Chang DCN (2004) Asymbiotic and symbiotic seed germination of Anoectochilus formosanus and Haemaria discolor and their $F_{1}$ hybrids. Bot Bull Acad Sin 45:143-147

Govaerts R (2018) World Checklist of Anoectochilus. Facilitated by the Royal Botanic Gardens, Kew. http://wcsp.science.kew.org/. Accessed 28 Oct 2018

Jiang JH, Lee Yl, Cubeta MA, Chen LC (2015) Characterization and colonization of endomycorrhizal Rhizoctonia fungi in the medicinal herb Anoectochilus formosanus (Orchidaceae). Mycorrhiza 25:431-445

Kusano S (1915) Experimental studies on the embryonal development in an angiosperm. J Col Agric Tokyo Imp Univ 6:7-120

Lee Yl, Lee N, Yeung CE, Chung MC (2005) Embryo development of Cypripedium formosanum in relation to seed germination in vitro. J Am Soc Hortic Sci 130:747-753

Lee Yl, Yeung EC, Lee N, Chung MC (2006) Embryo development in the lady's slipper orchid, Paphiopedilum delenatii, with emphasis on the ultrastructure of the suspensor. Ann Bot 98:1311-1319

Lee Yl, Yeung EC, Lee N, Lur CF, Chung MC (2007) Changes in endogenous abscisic acid levels and asymbiotic seed germination of a terrestrial orchid, Calanthe tricarinata Lindl. J Am Soc Hortic Sci 132:246-252

Lee Yl, Yeung EC, Lee N, Chung MC (2008) Embryology of Phalaenopsis amabilis var. formosa: embryo development. Bot Stud 49:139-146

Lee YI, Hsu ST, Yeung EC (2013) Orchid protocorm-like bodies are somatic embryos. Am J Bot 100:2121-2131

Miyoshi K, Sato T (1997) Removal of the pericarp and testa of seeds of Japonica and Indica rice (Oryza sativa) at various oxygen concentrations has opposite effects on germination. Physiol Plant 99:1-6

Murashige T, Skoog F (1962) A revised medium for rapid growth and bioassays with tabacco tissue culture. Physiol Plant 15:473-497

Nishimura G, Tamura M (1993) Seed coat formation in Apostasia nipponica. J Jpn Bot 68:219-223

Nishimura G, Yukawa T (2010) Dark material accumulation and sclerotization during seed coat formation in Vanilla planifolia Jacks: Ex Andrews (Orchidaceae). Bull Natl Mus Nat Sci Ser B 36:33-37

Pridgeon AM, Cribb PJ, Chase MW, Rasmussen FN (eds.) (2003) Genera Orchidacearum. vol. 3. Orchidoideae (Part 2), Vanilloideae. Oxford University Press, Oxford

Rasmussen HN (1995) Terrestrial orchids-from seed to mycotrophic plant. Cambridge University Press, Cambridge

Sato Y (1974) Embryological studies in the Japanese Epipactis (Orchidaceae). Sci Rep Tohoku Univ Ser IV (Biol) 37:33-45

Yam TW, Yeung EC, Ye XL, Zee SY, Arditti J (2002) Orchid embryos. In: Kull T, Arditti J (eds) Orchid biology: reviews and persectives VIII. Kluwer Academic Publisher, Dordrecht, pp 287-385

Yamazaki J, Myoshi K (2006) In vitro asymbiotic germination of immature seed and formation of protocorm by Cephalanthera falcata (Orchidaceae). Ann Bot 98:1197-1206

Yang CK, Lee YI (2014) The seed development of a mycoheterotrophic orchid, Cyrtosia javanica Blum. Bot Stud 55:44

Ye S, Shao Q, Zhang A (2017) Anoectochilus roxburghii: a review of its phytochemistry, pharmacology, and clinical applications. J Ethnopharmacol 209:184-202 
Yeung EC (1984) Histological and histochemical staining procedures. In: Vasil IK (ed) Cell culture and somatic cell genetics of plants. Academic Press, Orlando, pp 689-697

Yeung EC (2017) A perspective on orchid seed and protocorm development. Bot Stud 58:33

Yeung EC, Chan CKW (2015) The glycol methacrylate embedding resinsTechnovit 7100 and 8100 . Plant microtechniques and protocols. Springer International Publishing, New York. pp 67-82

Yeung EC, Law SK (1992) Embryology of Calypso bulbosa. II. Embryo development. Can J Bot 70:461-468
Yeung EC, Law SK (1997) Ovule and megagametophyte development in orchids. In: Arditti J, Pridgeon AM (eds) Orchid biology: reviews and perspectives VII. Kluwer Academic Pub, Dordrecht, pp 31-73

Yeung EC, Zee SY, Ye XL (1996) Embryology of Cymbidium sinense: Embryo development. Ann Bot 78:105-110

Yeung EC, Li YY, Lee YI (2018) Understanding seed and protocorm development in orchids. In: Lee YI, Yeung EC (eds) Orchid propagation: from laboratory to greenhouses-methods and protocols. Springer Protocols and Handbooks, Humana Press, New York, pp 3-26

\section{Submit your manuscript to a SpringerOpen ${ }^{\circ}$ journal and benefit from:}

- Convenient online submission

- Rigorous peer review

- Open access: articles freely available online

- High visibility within the field

- Retaining the copyright to your article

Submit your next manuscript at $\boldsymbol{\nabla}$ springeropen.com 